\title{
Experience with the CAM vision stimulator: preliminary report
}

\author{
H. E. WILLSHAW, A. MALMHEDEN, J. CLARKE, \\ A. WILLIAMS, AND L. DEAN \\ From the Orthoptic Departments of the Birmingham and Midland Eye Hospital \\ and the Birmingham Children's Hospital
}

SUMMARY Eighty-four children with at least 2 lines of amblyopia were treated with the CAM vision stimulator. $91 \%$ of the children who had received no previous amblyopia therapy showed improvement, $73 \%$ achieving $6 / 12$ vision or better. Of children in whom previous occlusion therapy had failed $73.8 \%$ improved. The treatment appears to be effective, rapid, and well tolerated. Our initial impressions have been sufficiently favourable to stimulate further clinical evaluation.

Amblyopia probably affects between $4 \%{ }^{1}$ and $7 \%{ }^{2}$ of children in this country. Our understanding of the pathophysiology of amblyopia has blossomed over the last 20 years, ${ }^{3-5}$ yet the treatment has remained essentially unchanged since $1746 .{ }^{6}$ Occlusion continues to be the mainstay of treatment, and though it is recognised to be both psychologically and educationally disruptive, alternative methods have not as yet proved sufficiently effective to supplant it. ${ }^{7}$ Recent reports of experience with a new, physiologically based, form of treatment have been encouraging. ${ }^{9}$ We report an independent, preliminary assessment of this treatment.

\section{Materials and methods}

Children attending the Orthoptic Departments of the Birmingham and Midland Eye Hospital and the Birmingham Childrens' Hospital were included in the study if they had 2 or more lines of amblyopiaas measured by linear optotypes-and were able to co-operate with treatment. All children had a full ophthalmological examination, and no child with anterior segment or fundus pathology commensurate with the visual acuity was included.

All the children were refracted under cyclopentolate cycloplegia, and full optical correction was prescribed. When the spectacles had been worn for at least 1 week, treatment was started. Each child was shown a series of high-contrast square-wave gratings of different spatial frequencies, and treat-

Correspondence to $\mathrm{Dr}$ H. E. Willshaw, Birmingham and Midland Eye Hospital, Church Street, Birmingham B3 2NS. ment was undertaken with the 3 smallest discernible gratings. Each in turn was rotated at 1 revolution per minute behind a clear Perspex cover on which the child drew or played pencil games under supervision. The session lasted 7 minutes and was repeated at weekly intervals for 4 weeks. If the visual acuity was still improving after 4 weeks, further weekly sessions were arranged. Otherwise treatment was discontinued at this stage.

The children had a full orthoptic examination at the beginning and end of treatment, and the visual acuity was measured before and after each session. Four weeks after treatment had been discontinued the children had a further orthoptic examination.

Between sessions the children received no additional treatment.

\section{Results}

Eighty-four children were included in the study. Their ages ranged from 3 years 4 months to 14 years 6 months with a mean of 6 years 7 months. Sixty-one children $(72.6 \%)$ had received previous amblyopia therapy in the form of either part-time or full-time occlusion. The remaining $23(27 \cdot 4 \%)$ were 'new' cases.

Sixty-two of the $84(73.8 \%)$ have attended for assessment 1 month after treatment was discontinued. Of the remainder 16 are continuing their treatment, and 6 have failed to attend for review.

The results are displayed in Figs. 1 and 2. The diagonal line in each case represents the 'no improvement' line, with improvement being recorded above the line and deterioration below. 


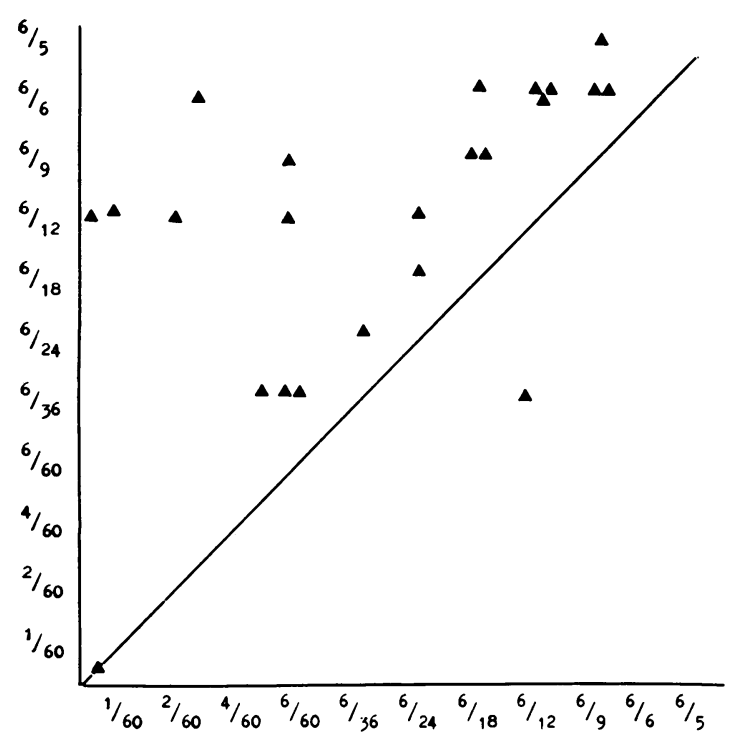

Fig. 1 Previously untreated patients: visual acuity at $6 \mathrm{~m}$.

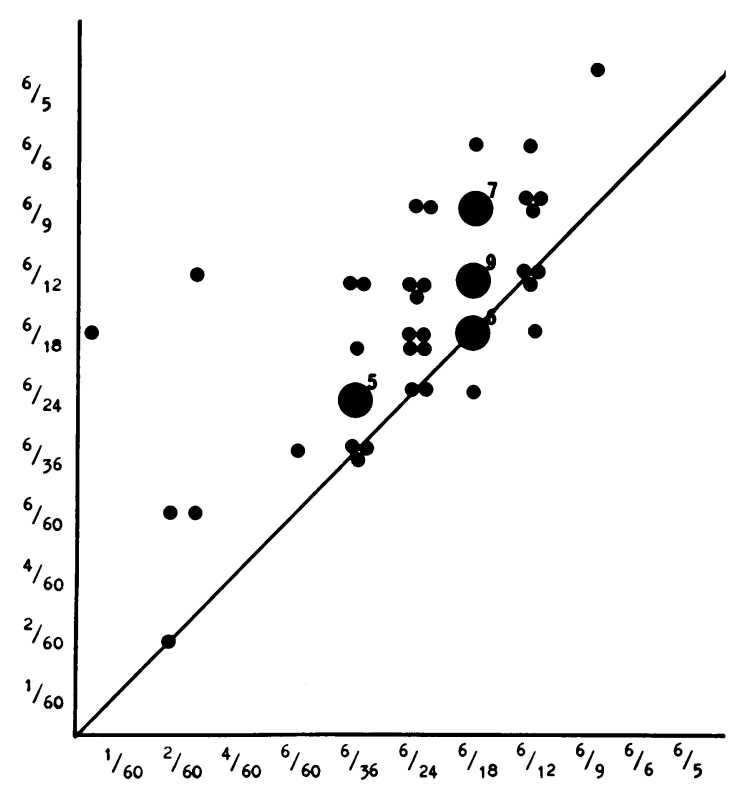

Fig. 2 Previously treated patients: visual acuity at $6 \mathrm{~m}$.

The results in children who had received no previous treatment are examined separately (Fig. 1). In $21(91 \%)$ the vision improved, in 1 the vision was unchanged, and in 1 there was considerable deterioration $(6 / 12$ to $6 / 36$ in 4 weeks). Eleven of the 21 achieved their improvement in 4 weeks, 2 required 5 weeks, 3 required 6,3 required 7,2 required 8 , and 1 child required 9 weeks. All the children who failed to achieve N5 vision initially showed improved near vision, including the girl whose distance vision deteriorated.

Among the 61 children with previous occlusion 14 failed to improve and 2 deteriorated. The 45 $(73.8 \%)$ children who improved showed generally more modest improvements, though there were some dramatic exceptions (Fig. 2). In 38 of the 61 only 4 treatment sessions were necessary, and in no case was more than 10 sessions needed. In all but 1 of these 'failed occlusion' children the near vision improved if it was not initially N5.

Fifteen previously untreated patients have been reviewed 4 weeks after the completion of treatment. Six have failed to maintain their visual improvement, but in only 2 was the regression more than 1 Snellen line, and neither of these have regressed to their pretreatment vision.

Forty-seven previously treated patients have also been followed up for 4 weeks after completion of treatment, and $18(38.3 \%)$ have failed to maintain their improvement. Indeed 15 of these 18 have reverted to their 'pre-CAM' vision within the 4-week follow-up period.

In this group there were no instances of diplopia, no increase in the angle of squint, and no failures of attendance during treatment.

\section{Discussion}

In children receiving amblyopia treatment for the first time the results are promising. $91 \%$ showed improvement in their distance vision, $73 \%$ achieving $6 / 12$ or better, 1 child from an initial vision of $\frac{1}{2} / 60$. These improvements were frequently obtained within 4 weeks and appear to be well maintained. ${ }^{10}$ The disturbance to normal education is limited, and there is no social embarrassment for the child, both factors of great importance in this age group. The good patient acceptance is mirrored by the $100 \%$ treatment completion rate.

In children who have had previous occlusion our results are similar to those originally reported, ${ }^{8}$ with $73.8 \%$ showing an improvement. Again these improvements were achieved much more rapidly than one would anticipate with occlusion, ${ }^{11}$ with, therefore, less disruption to normal life. However, in our children these results were not well maintained, with almost $40 \%$ reverting to their pretreatment vision. None the less, a maintained improvement in $60 \%$ of children with failed occlusion must still be regarded as encouraging.

The potential for this form of treatment is enormous, and it is important that extensive clinical experience is obtained before exploring this potential. It appears to offer a rapid, inexpensive, and 
successful form of treatment, with high patient acceptance and minimal social disruption.

Many features need further examination, including the optimum number and frequency of treatments, long-term maintenance of visual improvement, etc., and further studies will clarify these points. Our initial impression, however, is that the CAM vision stimulator may eventually replace occlusion as the first choice treatment of amblyopia.

We thank the Birmingham ophthalmologists for allowing us to examine their patients, Miss $\mathrm{J}$. Kempster for help in refracting the children, and Mrs P. Brooks for her secretarial help.

THE CAM vision stimulator was kindly supplied by Clement Clarke International Ltd.

\section{References}

${ }^{2}$ Adelstein AM, Scully J. Epidemiological aspects of squint. Br Med J 1967; iii: 334-8.

'Ingram RM, Traynar MJ, Walker C, Wilson JM. Screening for refractive errors at age 1 year: a pilot study. $\mathrm{Br} J$ Ophthalmol 1979; 63: 243-50.

${ }^{3}$ Wiesel TN, Hubel DH. Single cell responses in striate cortex of kittens deprived of vision in one eye. $J$ Neurophysiol 1963; 26: 1003-17.

${ }^{4}$ Von Noorden GK, Dowling JE, Ferguson DC. Experimental amblyopia in monkeys. Arch Ophthalmol 1970; 84: 206-14.

${ }^{5}$ Blakemore C, Van Sluyters R. Reversal of the physiological effects of monocular deprivation in kittens: further evidence for a sensitive period. J Physiol 1974; 198: 237-50.

${ }^{6}$ Buffon C, L de. Mémoires de L'Academie Royale des Sciences $1746 ; 231-4$.

${ }^{7}$ Willshaw HE, Johnson F. Penalisation as the primary treatment of strabismic amblyopia. Br Orthopt $J$ 1979; 36: 57-62.

${ }^{8}$ Banks RV, Campbell FW, Hess R, Watson PG. A new treatment for amblyopia. Br Orthopt $J$ 1978; 35: 1-12.

${ }^{9}$ Campbell FW, Hess R, Watson PG, Banks R. Preliminary results of a physiologically based treatment of amblyopia. $\mathrm{Br} J$ Ophthalmol 1978; 62: 748-55.

${ }^{10} \mathrm{Gregerson} \mathrm{E}$, Rindziunski E. Conventional occlusion in the treatment of squint amblyopia-a 10 year follow up. Acta Ophthalmol (Kbh) 1965; 43: 462-74.

${ }^{11}$ Catford GV, Amblyopic occlusion: the results of treatment. Trans Ophthalmol Soc UK 1967; 87: 179-93. 